\title{
Biofilm Formation and Indole-3-Acetic Acid Production by Two Rhizospheric Unicellular Cyanobacteria
}

\author{
Mehboob Ahmed ${ }^{1,2 *}$, Lucas J. Stal ${ }^{2,3}$, and Shahida Hasnain ${ }^{1}$ \\ ${ }^{1}$ Department of Microbiology and Molecular Genetics, University of the Punjab, Lahore-54590, Pakistan \\ ${ }^{2}$ Department of Marine Microbiology, Royal Netherlands Institute for Sea Research (NIOZ), NL-4400 AC Yerseke, The Netherlands \\ ${ }^{3}$ Department of Aquatic Microbiology, IBED, University of Amsterdam, 1090 GE Amsterdam, The Netherlands
}

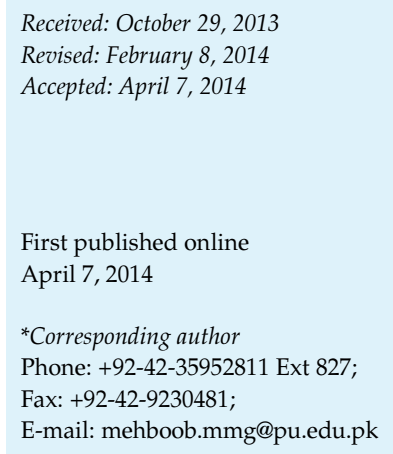

First published online April 7, 2014

*Corresponding author Phone: +92-42-35952811 Ext 827; Fax: +92-42-9230481;

E-mail: mehboob.mmg@pu.edu.pk

pISSN 1017-7825, eISSN 1738-8872

Copyright(C) 2014 by

The Korean Society for Microbiology and Biotechnology

\begin{abstract}
Microorganisms that live in the rhizosphere play a pivotal role in the functioning and maintenance of soil ecosystems. The study of rhizospheric cyanobacteria has been hampered by the difficulty to culture and maintain them in the laboratory. The present work investigated the production of the plant hormone indole-3-acetic acid (IAA) and the potential of biofilm formation on the rhizoplane of pea plants by two cyanobacterial strains, isolated from rice rhizosphere. The unicellular cyanobacteria Chroococcidiopsis sp. MMG-5 and Synechocystis sp. MMG-8 that were isolated from a rice rhizosphere, were investigated. Production of IAA by Chroococcidiopsis sp. MMG-5 and Synechocystis sp. MMG-8 was measured under experimental conditions ( $\mathrm{pH}$ and light). The bioactivity of the cyanobacterial auxin was demonstrated through the alteration of the rooting pattern of Pisum sativum seedlings. The increase in the concentration of L-tryptophan and the time that this amino acid was present in the medium resulted in a significant enhancement of the synthesis of IAA $(r>0.900$ at $p=0.01)$. There was also a significant correlation between the concentration of IAA in the supernatant of the cyanobacteria cultures and the root length and number of the pea seedlings. Observations made by confocal laser scanning microscopy revealed the presence of cyanobacteria on the surface of the roots and also provided evidence for the penetration of the cyanobacteria in the endorhizosphere. We show that the synthesis of IAA by Chroococcidiopsis sp. MMG-5 and Synechocystis sp. MMG-8 occurs under different environmental conditions and that the auxin is important for the development of the seedling roots and for establishing an intimate symbiosis between cyanobacteria and host plants.
\end{abstract}

Keywords: Auxin, bioassay, Chroococcidiopsis sp., cyanobacterial biofilms, indole-3-acetic acid, Pisum sativum, plant hormone, Synechocystis sp.

\section{Introduction}

Agricultural soil provides an excellent ecological niche for microbial diversity governed by the soil and type of vegetation [14]. In particular, the rhizosphere, soil close to plant roots, is considered to be an environment rich in substrates for microbes, particularly for those that are associated with the roots of plants, such as various heterotrophic bacteria and fungi, as well as phototrophs like cyanobacteria and microalgae [9]. Rhizospheric microbes actively respond to the variety of metabolites released by plant roots. These microbes along with their metabolites also interact with plant roots in a variety of beneficial, harmful, and harmless ways [32, 33]. These interactions can control not only plant growth and development but also alter the plant's susceptibility to disease and abiotic stress [33]. In return, the plants modify the rhizospheric environment by providing the microorganisms with substrate through root exudates [28]. Plants secrete more than $40 \%$ of their photosynthates in the form of root 
exudates that can be actively released from the root (including mucilage) and passively released (diffusive compounds) owing to osmotic differences between the soil solution and the cell [33, 42]. Soil microbes are sensitive to changes in the environmental conditions that prevail in the rhizosphere. Cyanobacteria are well-known for their capacity to produce a variety of secondary metabolites of which many are infochemicals [22]. Many cyanobacterial secondary metabolites influence plant growth and development [24]. Cyanobacteria have been reported to give a benefit to plants by producing growth-promoting substances (resembling auxin and giberellin), vitamins, polysaccharides, and antibacterial and antifungal compounds. Production of phytohormones is not limited to plants. Certain microbes, including cyanobacteria, produce all known phytohormones [42,44]. The capacity of microbes to synthesize secondary metabolites such as auxins varies with minor fluctuations of environmental conditions in the surroundings [10]. The microbes adapt to the rhizospheric conditions to sustain their growth and maintain their metabolic activity [7]. Auxin-producing cyanobacteria have been reported to stimulate plant growth in vitro [24], in a hydroponics system [31], as well as under field conditions [23]. Surprisingly, although cyanobacteria are phototrophic organisms, they are able to inhabit and live in the dark rhizosphere. Root colonization of cyanobacteria is not limited to the ectorhizoshpere (the soil immediately adjacent to the root) and rhizoplane (root epidermal and mucilage layer) but also extends to the endorhizosphere (root tissue including the endodermis and cortical layers) [2]. Some cyanobacteria penetrate the root cells and grow intracellularly [38]. The effectiveness of rhizospheric microbe at promoting growth depends on its density in the rhizosphere, and once a critical microbial density is reached then the biofilm as a whole acts as a plant growth-promoting unit [33]. Furthermore, owing to their extracellular polymeric coating, cyanobacteria have the ability to attach to solid substrates or to other organisms and form biofilms [26]. Pisum sativum is a dicot, commonly used as an experimental plant in many microbiological, physiological, genetical, and ecological studies $[41,43]$. Its seedlings with hairy roots are used in bioassays with phytohormones $[5,19]$. Thus, cyanobacteria that have the ability to produce auxin and form biofilms on roots may be interesting for biotechnological application in agriculture. The purpose of this study was to assess the capability of two unicellular rhizospheric cyanobacteria to form biofilms on seedling roots and to synthesize the plant hormone auxin under relevant environmental conditions (such as low $\mathrm{pH}$ and less light).

\section{Materials and Methods}

\section{Strains and Growth Conditions}

The unicellular cyanobacteria Chroococcidiopsis sp. MMG-5 and Synechocystis sp. MMG-8 have been isolated from rice rhizosphere in the agricultural fields of the University of Punjab, Lahore,

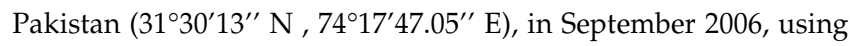
standard cyanobacterial isolation and purification techniques [2]. The isolates were characterized by $16 \mathrm{~S}$ rRNA gene sequencing technique, and the GenBank accession numbers are FJ839355 and FJ839359, respectively. Axenic cultures were maintained in BG-11 [39] medium, kept under constant conditions with light $\left(\sim 150 \mu \mathrm{E} / \mathrm{m}^{2} / \mathrm{s}\right)$ provided by four $18 \mathrm{~W}$ fluorescent tubes at a 16:8 light:dark cycle and the temperature maintained at $26 \pm 2^{\circ} \mathrm{C}$.

\section{Morphology}

The cyanobacteria were observed by light microscopy and confocal laser scanning microscopy (CLSM) following the methods described previously [2]. The cyanobacteria were dispersed in warm liquid agarose $(1 \%(\mathrm{w} / \mathrm{v}))$ on an object glass and covered with a cover slip and observed with a light microscope (Zeiss Axiophot, Oberkochen, Germany) using differential interference contrast (DIC) microscopy. CLSM was performed using a TCS-NT microscope (Leica, Heidelberg, Germany) equipped with an ArgonKrypton laser. Autofluorescence from cyanobacterial chlorophyll $a$ and phycobiliproteins was used for observation without staining. The organisms were excited by wavelength $488 \mathrm{~nm}$, and emitted wavelengths were collected with a $590 \mathrm{~nm}$ long-pass filter.

\section{Determination of Chlorophyll $a$ Concentration}

For the estimation of growth, chlorophyll $a$ was determined following the method of Tandeau de Marsac and Houmard [46]. Harvesting of the cyanobacteria was done by centrifugation at $10,000 \times g$ for $10 \mathrm{~min}$ at $4^{\circ} \mathrm{C}$. The pellets were extracted by $80 \%$ methanol for $2 \mathrm{~h}$ in the dark at $4^{\circ} \mathrm{C}$. The extract was centrifuged at $10,000 \times g$ for $10 \mathrm{~min}$ at $4^{\circ} \mathrm{C}$, and the absorbance of the supernatant was measured spectrophotometrically at $665 \mathrm{~nm}$ against $80 \%$ methanol. The chlorophyll content $(\mu \mathrm{g} / \mathrm{ml})$ was calculated from the absorption at $665 \mathrm{~nm}\left(\mathrm{OD}_{665 \mathrm{~nm}}\right) \times 13.9$.

\section{Extraction of IAA}

Released and intracellular auxins were extracted from the spent culture media and from the cyanobacterial cells, respectively, as reported previously [3, 42]. Briefly, 3-week-old cultures (incubated with $1,000 \mu \mathrm{g} / \mathrm{ml}$ of L-tryptophan supplementation) were harvested by centrifugation at $10,000 \times g$ for $20 \mathrm{~min}$ at $4^{\circ} \mathrm{C}$. For estimation of extracellular IAA, the $\mathrm{pH}$ of the supernatant was adjusted to 2.8 (using $1.0 \mathrm{M} \mathrm{HCl}$ ) and extracted three times with three volumes of ethyl acetate. The extracts were evaporated at $37^{\circ} \mathrm{C}$ using a rotary evaporator (Heidolph LABOROTA, Cole-Parmer, IL, USA) and the aqueous fraction during extraction was adjusted to $\mathrm{pH} 7.0$ (using $1.0 \mathrm{~N} \mathrm{NaOH}$ ) and extracted three times with watersaturated $n$-butanol, followed by drying in a rotary evaporator. 
The extracts obtained were filtered through membrane filters (Millipore, $0.45 \mu \mathrm{m}$ ). For intracellular IAA, the cyanobacterial cells were homogenized in liquid nitrogen using a mortar and pestle. IAA was extracted overnight at $4^{\circ} \mathrm{C}$ in $80 \%$ methanol containing $10 \mathrm{mg} / \mathrm{l}$ butylated hydroxytoluene as the antioxidant. The methanolic fraction was centrifuged at $5,000 \times g$ for $10 \mathrm{~min}$ at $4{ }^{\circ} \mathrm{C}$, followed by filtering through filters (nominal pore size $1.2 \mu \mathrm{m}$; GF/C, Whatman). The filtrate was partitioned with ethyl acetate and water-saturated $n$-butanol as described above. The organic phases were dried under a stream of nitrogen gas and the residues were re-dissolved in methanol. All extracts were stored at $-18^{\circ} \mathrm{C}$ and assayed within $48 \mathrm{~h}$.

\section{Determination of Concentration of IAA}

IAA was measured by the Salkowski colorimetric method [18]. Cyanobacteria were grown in BG-11 medium supplemented with L-tryptophan $(500 \mu \mathrm{g} / \mathrm{ml})$. After 18 days of incubation, the cultures were harvested by centrifugation at $10,000 \times g$ for $10 \mathrm{~min}$ at $4^{\circ} \mathrm{C}$. The spent medium was filter-sterilized (Millipore filter, $0.45 \mu \mathrm{m}$ ) and mixed with two parts of Salkowski reagent $(1 \mathrm{ml}$ of $0.05 \mathrm{M}$ $\mathrm{FeCl}_{3}$ mixed with $50 \mathrm{ml}$ of $35 \% \mathrm{HClO}_{4}$ ), and then incubated for $30 \mathrm{~min}$ in the dark at room temperature. The appearance of red color indicated the presence of an IAA. The absorption was measured spectrophotometrically at $535 \mathrm{~nm}$ against a control of $1 \mathrm{ml}$ culture medium and $2 \mathrm{ml}$ of Salkowski reagent. A standard curve was made from a concentration series of indole-3-acetic acid (3-indoleacetic acid; Sigma-Aldrich) solutions. All measurements were done in triplicate.

\section{Effect of L-Tryptophan on IAA Production}

IAA was determined in the culture medium at regular intervals during 5 weeks as described previously [3]. Each strain of cyanobacterium was inoculated in six flasks containing $100 \mathrm{ml}$ of BG-11 medium supplemented with L-tryptophan $(250,500,750$, $1,000,1,250$, and $1,500 \mu \mathrm{g} / \mathrm{ml})$. Another flask was used as the control and was not inoculated. Every week, cells from one flask were harvested for the estimation of cyanobacterial growth (chlorophyll $a$ ) and for the measurement of released IAA. Each experiment was performed in triplicate.

\section{Effect of pH on IAA Exudation}

The effect of $\mathrm{pH}$ on the synthesis and exudation of IAA by Chroococcidiopsis sp. MMG-5 and Synechocystis sp. MMG-8 was measured. For each of the two strains, five flasks were inoculated, containing $100 \mathrm{ml}$ of BG-11 medium supplemented with $500 \mu \mathrm{g} /$ $\mathrm{ml}$ L-tryptophan but adjusted to different $\mathrm{pH}$ values $(5,6,7,8$, and 9) by adding $\mathrm{HCl}$ or $\mathrm{NaOH}$. After three weeks of growth, the cultures were harvested and IAA was measured [3].

\section{Effect of Light-Dark Regime on IAA Production}

Chroococcidiopsis sp. MMG-5 and Synechocystis sp. MMG-8 were inoculated into $100 \mathrm{ml}$ of BG-11 medium supplemented with $500 \mu \mathrm{g} / \mathrm{ml}$ L-tryptophan. Cultures were grown for three weeks under four light-dark regimes: 16:8, 8:16, 24:0, and 0:24 h. Cultures were harvested and IAA was measured from the spent media [3].

\section{Effect of Nitrate on IAA Production}

The strains MMG-5 and MMG-8 were grown in BG-11 medium supplemented with $500 \mu \mathrm{g} / \mathrm{ml}$ L-tryptophan in two sets. The first set contained $1.5 \mathrm{~g} / 1 \mathrm{NaNO}_{3}$, whereas the second set lacked $\mathrm{NaNO}_{3}$. Cultures were harvested after three weeks of growth and IAA was measured in the spent media.

\section{Quantification of IAA by GC-MS}

Chroococcidiopsis sp. MMG-5 and Synechocystis sp. MMG-8 were grown for three weeks in BG-11 medium supplemented with $500 \mu \mathrm{g} / \mathrm{ml}$ L-tryptophan, after which $5 \mu \mathrm{g} / \mathrm{ml}$ of 5-methoxyindole-3-acetic acid (5-Me-IAA; Sigma-Aldrich) was added to the cultures as an internal standard. Both intracellular and extracellular IAAs were extracted and analyzed by GC-MS following the method of Gutierrez et al. [20].

\section{Root Bioassay}

The IAA bioactivity of both cyanobacterial strains was demonstrated by assessing the effect of culture supernatant on the root growth of pea ( $P$. sativum var. Climax), as described previously $[1,3]$. Pea seeds were obtained from the Punjab Seed Corporation, Lahore, Pakistan. Seeds were surface sterilized by washing them for $5 \mathrm{~min}$ in $0.1 \% \mathrm{HgCl}_{2}$ followed by repeated washing with sterile distilled water. Subsequently, the seeds (78 seeds) were placed in Petri dishes containing two layers of Whatman filter paper, which served to retain the moisture. Cultures of strains MMG-5 and MMG-8 incubated with 1,000 $\mu \mathrm{g} / \mathrm{ml}$ of L-tryptophan were centrifuged at $10,000 \times g$ for $10 \mathrm{~min}$ in sterile tubes. Filter-sterilized (Millipore filter, $0.45 \mu \mathrm{m})$ supernatant $(1$, 2.5 , and $5 \mathrm{ml}$ ) was added to Petri dishes along with MilliQ water (Millipore Corporation, MA, USA) to make a total volume of $10 \mathrm{ml}$. The Petri dishes were kept in the dark for germination of the pea seeds. After germination the dishes were transferred to a 16:8 light:dark $\left(200 \mu \mathrm{E} / \mathrm{m}^{2} / \mathrm{s}\right)$ regime. The number and length of the roots of the seedlings were determined in triplicate after 10 days. These measurements were repeated with supplementation of filter-sterilized supernatant of the cyanobacteria from cultures of different age (1-6 weeks). IAA was measured colorimetrically with the Salkawski reagent from the spent media at each measurement.

\section{Biofilm Formation}

Pea seeds were germinated in Petri dishes under axenic conditions for 10 days (16:8 h light:dark period, and light intensity of $200 \mu \mathrm{E} / \mathrm{m}^{2} / \mathrm{s}$ ). Subsequently, the seedlings were suspended in $50 \mathrm{ml}$ tubes with their roots immersed in $25 \mathrm{ml}$ of 10-fold diluted BG11 medium. Three-week-old cyanobacteria cultures were harvested by centrifugation at $10,000 \times g$ for $10 \mathrm{~min}$ and suspended in $10 \mathrm{ml}$ of sterile MilliQ water (Millipore Corporation, MA, USA). Cyanobacteria were added to the suspension of seedling roots to a 
final amount of $2 \mu \mathrm{g}$ chl- $a / \mathrm{ml}$. Tubes were incubated at $25^{\circ} \mathrm{C}$ at a $16: 8 \mathrm{~h}$ light-dark cycle $\left(200 \mu \mathrm{E} / \mathrm{m}^{2} / \mathrm{s}\right.$ light intensity) for 7 days to allow for biofilm formation on the seedling roots. Subsequently, the seedling roots were excised, and loosely attached cyanobacterial cells were removed by washing with sterile MilliQ water by squeeze bottle. The presence of cyanobacterial biofilm was observed by CLSM [2].

\section{Confocal Laser Scanning Microscopy}

CLSM of the roots and the image analysis were done as previously described $[2,4]$. The root cells were stained overnight with the fluorescent dye 5-(4,6-dichlorotriazinyl) aminofluores (DTAF; Cat. \# D-16; Invitrogen Corporations, USA) (1 mM). Excess stain was removed by washing twice with phosphate buffer saline, $\mathrm{pH} 8(1 \times)$, followed by two washings with $0.1 \mathrm{M}$ carbonate buffer, $\mathrm{pH}$ 9. CLSM was performed using a TCS-NT microscope (Leica, Heidelberg, Germany) equipped with an Argon-Krypton laser. For simultaneous imaging of emission fluorescence from DTAF and autofluorescence of chlorophyll $a$ and phycobiliproteins, root sections were excited by $488 \mathrm{~nm}$. Emitted wavelengths from DTAF were collected using band-pass filter 530/30 and autofluorescence with a 590-nm-long pass filter. Images were obtained from the same field at different depths. To visualize the cyanobacterial colonization, the root surface was observed, and a stack of images was generated to a depth of 10$20 \mu \mathrm{m}$. The acquired images were analyzed with Leica TCS NT/ SP scanware (ver. 1.6.587) software. Overlaid images were generated by the outputs of two channels and a maximum projection algorithm was applied. All figures were produced and edited with Adobe Photoshop CS3 ver. 10.0.1.

\section{Statistical Analysis}

Data were statistically analyzed using the IBM SPSS personal computer statistical package (ver. 20; SPSS Inc, Chicago, IL, USA). The Student's $t$-test was performed to measure significant difference between the intra- and extracellular IAA pools $(p<0.05)$. Analysis of variance (ANOVA) was performed, and the means were separated using Duncan's multiple range test $(p<0.05)$. The degree of association of IAA with precursor or time was determined by Pearson's correlation $(p<0.05$ and 0.01$)$.

\section{Results}

\section{Strain Characteristics}

The two strains of cyanobacteria grew differently in BG11 medium. Chroococcidiopsis sp. MMG-5 formed aggregates (Fig. 1A), while Synechocystis sp. MMG-8 grew homogenously (Fig. 1B).

\section{Effects of Culture Age and L-Tryptophan Concentration on IAA Production}

Colorimetric analysis of the cyanobacterial culture

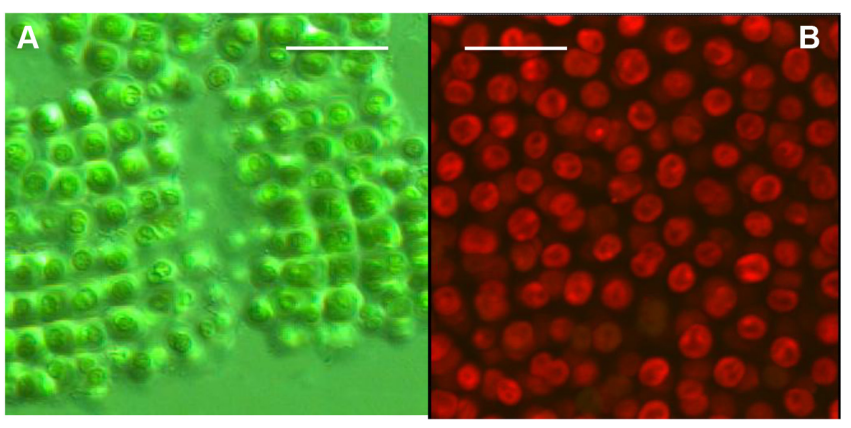

Fig. 1. Morphological characteristics of cyanobacterial strains (A) Chroococcidiopsis sp. MMG-5 under differential interference contrast (DIC) microscopy and (B) Synechocystis sp. MMG-8 under confocal laser scanning microscopy.

Bars $=10 \mu \mathrm{m}$.

supernatants revealed that both tested parameters (i.e. culture age and initial L-tryptophan concentration) in media significantly (ANOVA, $p<0.05$ ) affected IAA production by the two cyanobacteria. The estimated IAA increased with culture age $(r=0.986,-0.995, p=0.01)$ and the concentration of the precursor L-tryptophan $(\mathrm{r}=0.955-0.977, p=0.01)$ (Tables 1 and 2). In both cyanobacteria, the highest concentration of IAA was detected after 5 weeks of growth and with $1.5 \mathrm{mg} / \mathrm{ml}$ of L-tryptophan, amounting to 38.2 and $66.0 \mu \mathrm{g} / \mathrm{g}$ chl- $a$ of IAA in Chroococcidiopsis sp. MMG-5 and Synechocystis sp. MMG-8, respectively. The IAA production rate depended on the initial L-tryptophan concentration in the media. In media with $\leq 500 \mu \mathrm{g} / \mathrm{g}$ chl- $a$ of L-tryptophan supplementation, the IAA production rate was up to $6 \mu \mathrm{g} / \mathrm{g}$ chl- $a /$ week, whereas in media with $>500 \mu \mathrm{g} / \mathrm{g}$ chl- $a$ of L-tryptophan, the IAA production rate was higher than $14 \mu \mathrm{g} / \mathrm{g}$ chl- $a /$ week after 1 week of incubation.

\section{Intra- and Extracellular IAAs}

Both strains of cyanobacteria accumulated IAA intracellularly and released it in the medium during the 5 weeks of the experiment and showed a similar pattern of gradual increase in released and intracellular IAA with culture age (Figs. 2A and 2B). The maximum extracellular IAA was $60 \mu \mathrm{g} / \mathrm{g}$ chl$a$ in Synechocystis sp. MMG-8 after 5 weeks of cultivation, which was 33\% higher than the extracellular IAA produced by strain MMG-5 (45 $\mu \mathrm{g} / \mathrm{g}$ chl- $a$ ) during the same cultivation time. The intracellular IAA concentration was in the same order of magnitude in both cyanobacteria. The maximum intracellular IAA in MMG-8 cultures of 5 weeks was up to $31 \mu \mathrm{g} / \mathrm{g}$ chl- $a, 14 \%$ higher than the $27 \mu \mathrm{g} / \mathrm{g}$ chl- $a$ that was in strain MMG-5 of the same age. 
Table 1. Time course of auxin concentration in Chroococcidiopsis sp. MMG-5 cultures with different amounts of tryptophan.

\begin{tabular}{|c|c|c|c|c|c|c|c|}
\hline \multirow{2}{*}{$\begin{array}{c}\text { Time } \\
\text { (weeks) }\end{array}$} & \multicolumn{6}{|c|}{ Initial tryptophan concentration $(\mu \mathrm{g} / \mathrm{g}$ chl- $a$ ) } & \multirow{2}{*}{$\begin{array}{c}\text { Correlation } \\
\text { coefficients } \\
\qquad(\mathrm{r})^{\mathrm{a}}\end{array}$} \\
\hline & 250 & 500 & 750 & 1,000 & 1,250 & 1,500 & \\
\hline 1 & $1.58 \pm 0.055$ & $3.87 \pm 0.058$ & $4.92 \pm 0.085$ & $9.68 \pm 0.155$ & $11.7 \pm 0.179$ & $11.43 \pm 0.149$ & $0.965^{* *}$ \\
\hline 2 & $3.67 \pm 0.053$ & $8.32 \pm 0.165$ & $11.9 \pm 0.281$ & $13.8 \pm 0.381$ & $15.3 \pm 0.505$ & $17.69 \pm 0.455$ & $0.977^{* *}$ \\
\hline 3 & $4.86 \pm 0.073$ & $14.3 \pm 0.228$ & $18 \pm 0.464$ & $22.95 \pm 0.518$ & $23.22 \pm 0.720$ & $28.94 \pm 0.736$ & $0.965^{* *}$ \\
\hline 4 & $5.81 \pm 0.065$ & $16.12 \pm 0.264$ & $23.2 \pm 0.608$ & $28.57 \pm 0.815$ & $31.88 \pm 0.908$ & $32.99 \pm 0.980$ & $0.959^{* *}$ \\
\hline 5 & $7.37 \pm 0.060$ & $19.75 \pm 0.170$ & $25.65 \pm 0.530$ & $34.42 \pm 1.116$ & $35.68 \pm 1.390$ & $38.2 \pm 1.289$ & $0.955^{* *}$ \\
\hline $\begin{array}{c}\text { Correlation } \\
\text { coefficients } \\
(\mathrm{r})^{\mathrm{b}}\end{array}$ & $0.991^{* *}$ & $0.986^{* *}$ & $0.987^{* *}$ & $0.995^{* *}$ & $0.990^{* *}$ & $0.986^{* *}$ & \\
\hline
\end{tabular}

${ }^{a}$ Correlation coefficients (r) of initial tryptophan concentration with given incubation time.

${ }^{b}$ Correlation coefficients ( $r$ ) of incubation time with given initial tryptophan concentration.

Mean \pm SE of three replicates. ${ }^{* *}$ Correlation is significant at the 0.01 level; ${ }^{*}$ Correlation is significant at the 0.05 level.

Table 2. Time course of auxin concentration in Synechocystis sp. MMG-8 cultures with different amounts of tryptophan.

\begin{tabular}{|c|c|c|c|c|c|c|c|}
\hline \multirow{2}{*}{$\begin{array}{c}\text { Time } \\
\text { (Weeks) }\end{array}$} & \multicolumn{6}{|c|}{ Initial tryptophan concentration ( $\mu \mathrm{g} / \mathrm{g}$ chl-a) } & \multirow{2}{*}{$\begin{array}{l}\text { Correlation } \\
\text { coefficients } \\
(\mathrm{r})^{\mathrm{a}}\end{array}$} \\
\hline & 250 & 500 & 750 & 1,000 & 1250 & 1,500 & \\
\hline 1 & $3.87 \pm 0.136$ & $5.48 \pm 0.121$ & $8.53 \pm 0.205$ & $9.24 \pm 0.223$ & $13.27 \pm 0.115$ & $14.38 \pm 0.256$ & $0.912^{*}$ \\
\hline 2 & $7.66 \pm 0.066$ & $9.77 \pm 0.078$ & $16.4 \pm 0.088$ & $20.09 \pm 0.049$ & $23.96 \pm 0.056$ & $28.57 \pm 0.102$ & $0.995^{* *}$ \\
\hline 3 & $9.77 \pm 0.057$ & $16.54 \pm 0.033$ & $20.83 \pm 0.032$ & $22.85 \pm 0.033$ & $32.07 \pm 0.045$ & $37.97 \pm 0.093$ & $0.987^{* *}$ \\
\hline 4 & $13.27 \pm 0.052$ & $23.52 \pm 0.034$ & $28.47 \pm 0.045$ & $35.18 \pm 0.041$ & $44.42 \pm 0.033$ & $60.27 \pm 0.083$ & $0.983^{* *}$ \\
\hline 5 & $14.52 \pm 0.063$ & $28.38 \pm 0.033$ & $34.14 \pm 0.011$ & $38.22 \pm 0.000$ & $48.77 \pm 0.000$ & $66 \pm 0.066$ & $0.977^{* *}$ \\
\hline $\begin{array}{c}\text { Correlation } \\
\text { coefficients } \\
(\mathrm{r})^{\mathrm{b}}\end{array}$ & $0.989^{* *}$ & $0.983^{* *}$ & $0.991^{* *}$ & $0.980^{* *}$ & $0.992^{* *}$ & $0.987^{* *}$ & \\
\hline
\end{tabular}

${ }^{\text {a }}$ Correlation coefficients ( $r$ ) of initial tryptophan concentration with given incubation time.

${ }^{\mathrm{b}}$ Correlation coefficients (r) of incubation time with given initial tryptophan concentration.

Mean \pm SE of three replicates. ${ }^{* *}$ Correlation is significant at the 0.01 level; ${ }^{*}$ Correlation is significant at the 0.05 level.

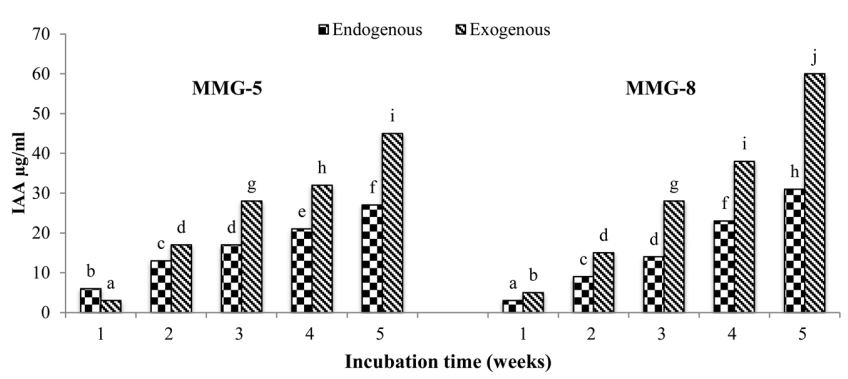

Fig. 2. Intra- and extracellular IAAs.

Mean values of three replicates. Different letters indicate significant difference between treatments, using Duncan's multiple range test $(p=0.05)$.

\section{Effect of $\mathrm{pH}$ on IAA Synthesis}

The $\mathrm{pH}$ of the medium significantly affected the synthesis of IAA. IAA production in both cyanobacteria was enhanced by an acidic $\mathrm{pH}$. Chroococcidiopsis sp. MMG-5 produced the highest amount of IAA (up to $43 \mu \mathrm{g} / \mathrm{g}$ chl- $a$ ) at $\mathrm{pH}$ 6, whereas Synechocystis sp. MMG-8 exuded the highest amount of IAA (more than $45 \mu \mathrm{g} / \mathrm{g}$ chl- $a$ ) at pH 5 . Quantities of IAA decreased gradually with an increase in media $\mathrm{pH}$ up to 9 (Table 3).

\section{Effect of Light Regime on IAA Synthesis}

The light:dark period significantly (ANOVA, $p<0.05$ ) affected IAA production by the two cyanobacteria. The amount of IAA produced in cultures grown under 8:16 h light:dark was significantly higher than in cultures grown under any of the other three light regimes (continuous light, continuous dark, and 16:8 h light:dark). The maximum amount of IAA was up to $40 \mu \mathrm{g} / \mathrm{g}$ chl- $a$ for both 
Table 3. Effect of growth conditions ( $\mathrm{pH}$, light:dark period, and nitrates) on auxin biosynthesis ( $\mu \mathrm{g} / \mathrm{g}$ chl-a) by cyanobacterial strains.

\begin{tabular}{|c|c|c|c|c|c|c|c|c|c|c|c|}
\hline \multirow{2}{*}{ Strains } & \multicolumn{5}{|c|}{$\mathrm{pH}$} & \multicolumn{4}{|c|}{ Light } & \multicolumn{2}{|c|}{ Nitrates } \\
\hline & 5 & 6 & 7 & 8 & 9 & 16:08 & $8: 16$ & $\mathrm{CL}$ & $\mathrm{CD}$ & $\mathrm{N}+$ & N- \\
\hline MMG-5 & 39 & 43 & 30 & 14 & 6 & 33 & 40 & 34 & 0 & 32 & 25 \\
\hline & $\pm 2.12(\mathrm{e})$ & $\pm 2.36(\mathrm{f})$ & $\pm 1.24(\mathrm{~d})$ & $\pm 1.17(b)$ & $\pm 0.77(\mathrm{a})$ & $\pm 0.83(\mathrm{~b})$ & $\pm 1.54(\mathrm{~d})$ & $\pm 2.33(\mathrm{~b})$ & $\pm 0.00(\mathrm{a})$ & \pm 1.29 (c) & $\pm 1.12(b)$ \\
\hline MMG-8 & $\begin{array}{c}45 \\
\pm 1.73(\mathrm{f})\end{array}$ & $\begin{array}{c}37 \\
\pm 2.43(\mathrm{e})\end{array}$ & $\begin{array}{c}30 \\
\pm 1.92(\mathrm{~d})\end{array}$ & $\begin{array}{c}20 \\
\pm 1.02 \text { (c) }\end{array}$ & $\begin{array}{c}5 \\
\pm 0.85(\mathrm{a})\end{array}$ & $\begin{array}{c}37 \\
\pm 1.22(\mathrm{~cd})\end{array}$ & $\begin{array}{c}42 \\
\pm 1.77(\mathrm{~d})\end{array}$ & $\begin{array}{c}35 \\
\pm 1.26(\mathrm{~b})\end{array}$ & $\begin{array}{c}0 \\
\pm 0.00 \text { (a) }\end{array}$ & $\begin{array}{c}28 \\
\pm 1.88(\mathrm{~b})\end{array}$ & $\begin{array}{c}0 \\
\pm 0.00 \text { (a) }\end{array}$ \\
\hline
\end{tabular}

16:08, 8:16 = light:dark period in hours; $\mathrm{CL}=$ complete light; $\mathrm{CD}=$ complete dark.

Mean values of three replicates. Different letters indicate significant difference between growth conditions, using Duncan's multiple range test $(p<0.05)$.

Chroococcidiopsis sp. MMG-5 and Synechocystis sp. MMG-8 grown under $8: 16 \mathrm{~h}$ light:dark. There was a marginal difference between the production of IAA by cultures grown under 16:8 h light:dark and cultures grown under continuous light. The cyanobacteria did not grow in the dark and, consequently, no IAA was produced (Table 3).

\section{Effect of Nitrate on IAA Synthesis}

Chroococcidiopsis sp. MMG-5 could grow without combined nitrogen and produced IAA under these conditions. IAA production was significantly higher (ANOVA, $p<0.05$ ) $(28 \%)$ in medium containing nitrate. Synechocystis sp. MMG-8 was unable to grow without combined nitrogen (Table 3).

\section{Quantification of IAA by GC-MS}

Extracts of intracellular and extracellular auxins were analyzed by using GC-MS in order to verify and quantify the IAA. The results confirmed the presence of intra- and extracellular IAAs in both strains. The amount of extracellular

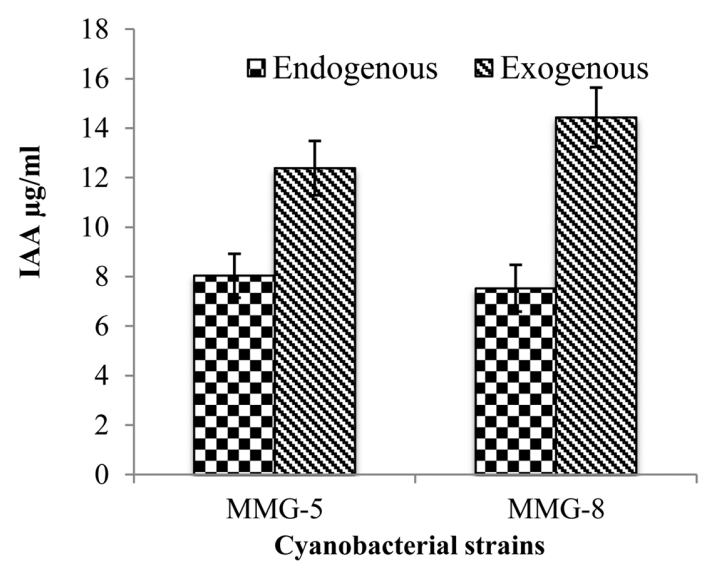

Fig. 3. Comparison of intra- and extracellular IAAs in Chroococcidiopsis sp. MMG-5 and Synechocystis sp. MMG-8 as analyzed by GC-MS.
IAA in strain MMG-8 was $17 \%$ higher than in strain MMG5 (Fig. 3). There was no difference in intracellular IAA between both strains.

\section{Effect of Supernatant on Root Length and Number of Lateral Roots}

Cyanobacterial supernatant containing high concentrations of IAA gave a negative effect on root length when compared with sterile growth medium. Five milliliters of medium supernatant of Chroococcidiopsis sp. MMG-5 containing $1.58 \mu \mathrm{g} / \mathrm{g}$ chl- $a$ of IAA resulted in an increase of root length (up to $60 \%$ ) in one week, as compared with the nonamended control. The increase of root length became less with age of the culture and disappeared after 5 weeks, while after 6 weeks of growth root length started to decrease $(\mathrm{r}=-0.995, p=0.01)$. Treatment with $1 \mathrm{ml}$ of supernatant resulted in a gradual increase in root length with culture age (i.e., increase in IAA) with a significant positive correlation of 0.974 at $p=0.01$ (Fig. 4A). When using $1 \mathrm{ml}$ of supernatant of Synechocystis sp. MMG-8, root length increased with a maximum of $81 \%$ after 3 weeks of growth, whereas 2.5 and $5 \mathrm{ml}$ did not result in an increase of root length, and after 5 weeks of growth the roots became even shorter than in the control (Fig. 4B).

The number of lateral roots increased when cyanobacterial culture supernatant was added, and a significant positive correlation between the number of lateral roots and the concentration of IAA was found. Five milliliters of Chroococcidiopsis sp. MMG-5 cultural supernatant after 5 and 6 weeks of growth resulted in the highest increase in the number of roots (156\% and $140 \%$, respectively), as compared with the control (Fig. 5A). Synechocystis sp. MMG-8 also increased the number of roots with culture age and the volume of supernatant added. The highest stimulation was with $5 \mathrm{ml}$ of supernatant, increasing 149\%, $152 \%, 192 \%$, and $167 \%$ after $3,4,5$, and 6 weeks of growth, respectively. The correlation of IAA concentration and root number was highly significant $(r=0.995, p=0.01)$ (Fig. 5B). 

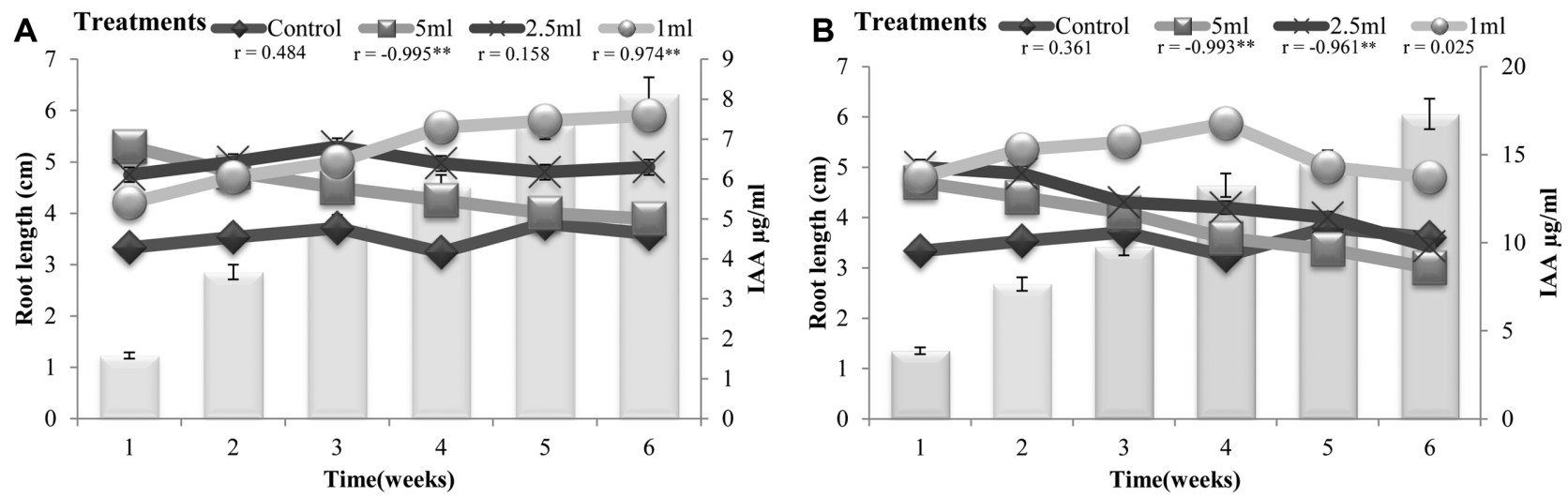

Fig. 4. Effect of the volume of spent media $(5,2.5$, and $1 \mathrm{ml})$ of auxin-producing cyanobacteria on the root length of $P$. sativum. The histograms represent auxin content of strains. (A) Chroococcidiopsis sp. MMG-5 and (B) Synechocystis sp. MMG-8. Mean of three replicates; Correlation coefficient $(\mathrm{r})$ between IAA and root length in different treatments (values beneath the legends). $\left({ }^{* *}\right.$ Correlation is significant at the 0.01 level; *Correlation is significant at the 0.05 level).
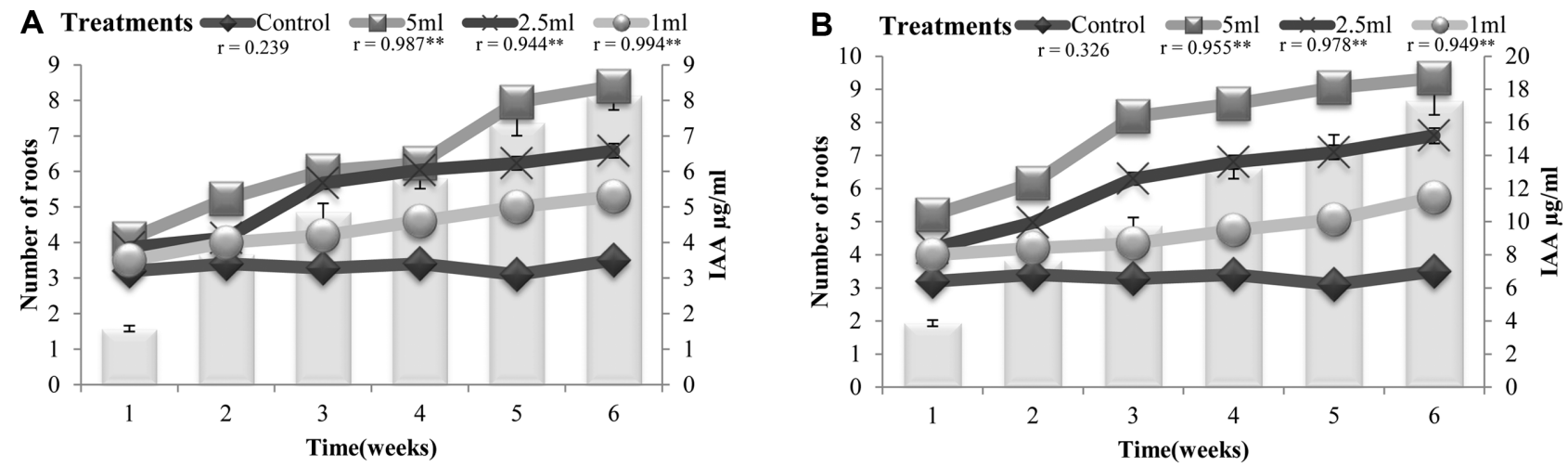

Fig. 5. Effect of the volume of spent media $(5,2.5$, and $1 \mathrm{ml})$ of auxin-producing cyanobacteria on root number of $P$. sativum.

The histograms represent auxin content of the cyanobacteria. (A) Synechocystis sp. MMG-8 and (B) Chroococcidiopsis sp. MMG-5. Mean of three replicates; Correlation coefficient (r) between IAA and number of roots in different treatments (values beneath the legends). $\left({ }^{* *} \mathrm{Correlation}\right.$ is significant at the 0.01 level; * Correlation is significant at the 0.05 level).

\section{Formation of Biofilms on the Rhizoplane of Pisum sativum Seedlings}

The cyanobacteria showed ability to colonize the rhizoplane. Chroococcidiopsis sp. MMG-5 extensively colonized the root surface and concentrated in the grooves between adjacent surface cells (Figs. 6A and 6B). Synechocystis sp. MMG-8 was scattered on the root surface but sometimes formed colonies (Figs. 6C and 6D). Furthermore, the orthogonal sectioning by CLSM illustrates how the cyanobacteria invaded the epidermis and the cortex region, because they appeared inside the root cells or underneath the outermost layer. Chroococcidiopsis sp. MMG-5 was mainly present at a depth of $10-15 \mu \mathrm{m}$ inside the root cells (Fig. 7A). Synechocystis penetrated the plant cells to a depth of 5$7 \mu \mathrm{m}$ (Fig. 7B).

\section{Discussion}

This study shows the ability of rhizospheric unicellular cyanobacteria to produce IAA and to colonize the roots, forming a thick biofilm. These two traits are considered to be pivotal for rhizospheric microbes, and any microorganism possessing these abilities should be successful in agricultural ecosystems [35].

Cyanobacteria have the ability to attach to surfaces through their extracellular polysaccharides. Such cyanobacteria are considered as important colonizers of surfaces and initiate the development of biofilms [17]. In order to allow the establishment of an intimate association of rhizospheric microorganisms, the plant root surface acts as the substrate to which microbes attach. The roots assist in this process by 

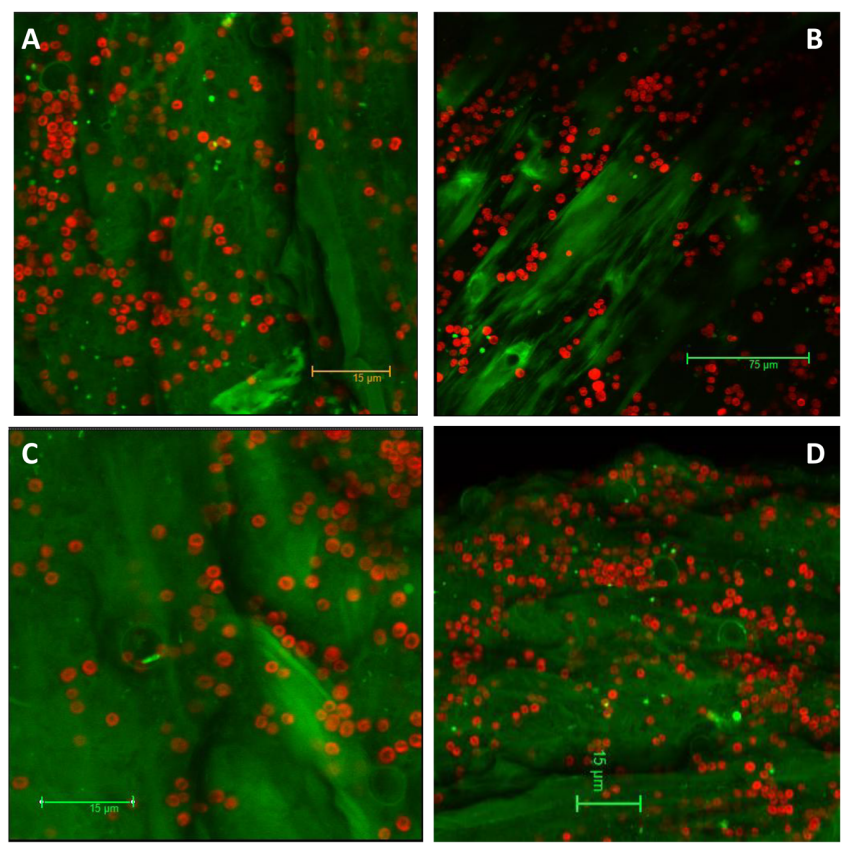

Fig. 6. Rhizoplane colonization by cyanobacteria (A and B) Chroococcidiopsis sp. MMG-5 and (C and D) Synechocystis sp. MMG-8.

Images obtained by a confocal laser scanning microscope. Green shows plant root cells stained with DTAF. Red shows cyanobacterial cells.

exuding a variety of signal compounds that attract the soil microorganisms [6]. The formation of a biofilm on the roots is an important trait of rhizospheric microorganisms, which prevents them from being dissociated from the plant caused by various chemical, biological, or physical processes in the soil [13]. Colonization of microbes on the plant root surface is not uniform, but instead occurs in patches along the root, which ultimately covers $\sim 15-40 \%$ of the total plant root surface [32]. The formation of a biofilm depends on several factors such as the number of attached cells per area of root surface, ability to withstand abrasive forces, competition with other microorganisms, and the potential to penetrate the root cells. Both of the investigated cyanobacteria colonized the rhizoplane. Once a biofilm formed on the rhizoplane, the cyanobacteria started to penetrate the root and colonized intracellular spaces or even penetrated the root cells or endorhizosphere (root tissue including the endodermis and cortical layers), probably in order to establish a more intimate association. It is not clear what the advantage of the penetration of the root cells is, nor what the mechanism behind it is. It has been suggested that proteolytic enzymes play a role in the degradation of the plant cell wall, thereby allowing the organism to enter the cell, but it could also be achieved by mechanical force [2, 34]. Furthermore, the extracellular auxins have been reported to up-regulate the production of cellulases and hemicelluloses in plants, which ultimately leads to the disintegration of the cell wall. Such weak patches might be used by microbes to penetrate the plant roots [20].

The most common pathway for IAA biosynthesis in plants and microorganisms is from L-tryptophan [42]. Both strains of cyanobacteria produced IAA only in the presence of L-tryptophan. Under natural conditions, the plant roots are the source of L-tryptophan, provided in the form of root exudates that serve as the substrate for the rhizospheric microorganisms. Cyanobacteria have been reported to synthesize IAA from L-tryptophan, and it depends on its concentration as well as culture age [3, 42]. Synechocystis sp. MMG-8 converted up to $4.5 \%$ of L-tryptophan to IAA. The metabolism of cyanobacteria is sensitive to environmental factors such as $\mathrm{pH}$ and light [37]. This became apparent by the effect of $\mathrm{pH}$ and light on the IAA biosynthesis. Generally, cyanobacteria prefer neutral or alkaline $\mathrm{pH}$ for growth [38], but low $\mathrm{pH}$ appeared to be favorable for optimal auxin production. It is well-established that the rhizosphere is generally characterized by a low $\mathrm{pH}(\mathrm{pH}$ 5.5), and many microbial genes involved in the interaction with plants are expressed higher at this $\mathrm{pH}$. The key gene for auxin biosynthesis (ipdC) is highly expressed at low $\mathrm{pH}[16$, $40,48]$. The light:dark regime is an important factor for cyanobacteria, and the metabolic activities are generally stimulated with the increase of the photoperiod [45]. A considerable difference was observed in auxin biosynthesis by the cyanobacteria incubated under various light:dark regimes. Maximum IAA was detected under a $8: 16 \mathrm{~h}$ light:dark regime. Light is directly involved in controlling the auxin levels in plants by regulating the auxin synthesis genes and translocation of auxins throughout the plants [21]. Light regulates the genes that code for enzymes involved in auxin synthesis and proteins involved in auxin translocation such as PIN-formed proteins (PIN) and Pglycoprotein(PGP) [21]. Genes whose products are involved in tryptophan-dependent IAA biosynthesis are especially under control by environmental light. By positive and negative regulation of auxin biosynthesis genes, the plant maintains a certain auxin concentration, according to what its developmental stage requires [30, 47]. Auxins, and especially IAA, are sensitive to light and are readily degraded through photolysis $[15,27]$. Compared with light:dark cycles with long dark periods, the relatively low amounts of IAA that were found after the long exposure of the cyanobacteria to light might have been the result of photolysis of IAA. 

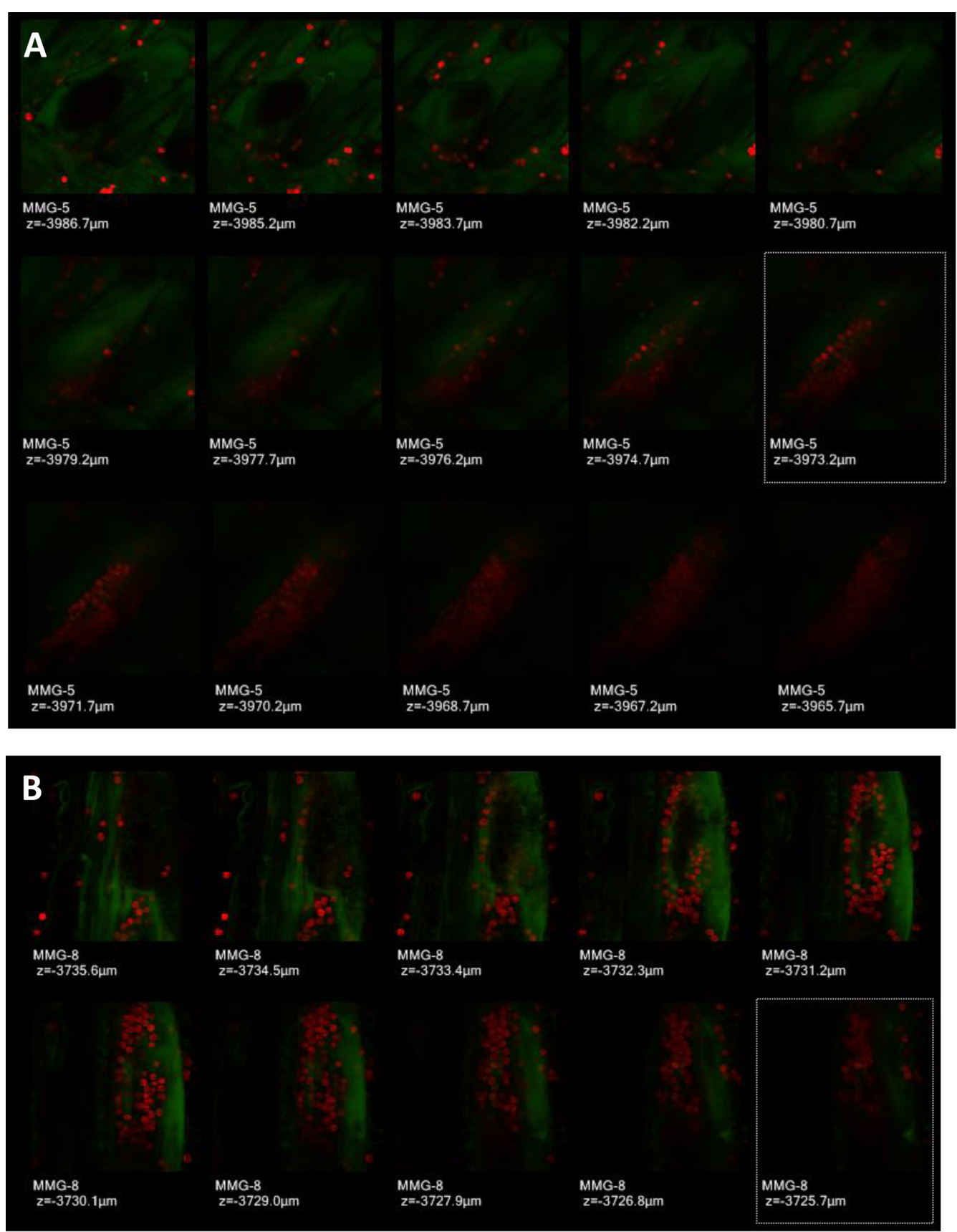

Fig. 7. Display windows of a Z stack in XY horizontal CLSM sections of (A) Chroococcidiopsis sp. MMG-5 and (B) Synechocystis sp. MMG-8 (red) with seedling roots (green).

Each slice represents an image at a different depth above the cell surface.

The possible reasons for the lower IAA yield in the absence of nitrate might be that (i) it restricted growth, (ii) tryptophan appeared to inhibit nitrogen fixation [36], and (iii) the fixation of nitrogen may have prevented the cells of synthesizing IAA, thus resulting in a low IAA in the supernatant. IAA measured by GC-MS gave significantly lower amounts than the colorimetric method (Salkowski's reagent). The difference between the GC-MS technique and the colorimetric assay is attributed to the fact that the former only measures the amount of IAA, whereas the Salkowski reagent also reacts with other indolic compounds and therefore is a measure of all auxins present [20, 42]. 
Hence, both methods do not measure the same, and the results indicate that other auxins than IAA are produced and may be involved in the observed effects on the root development.

Like other phytohormones, auxins are a group of important signaling molecules involved in the interaction between rhizospheric microbes and plants that affect plants even at very low concentrations $\left(10^{-5}-10^{-6} \mathrm{M}\right)[11,25]$. Roots are the most sensitive parts of plants with respect to the effect of auxins. Hence, root length and the number of lateral roots have been used as a bioassay for auxins, particularly for IAA [8]. Different volumes of sterile supernatant from the growth medium of cyanobacterial cultures of different age were used in the root bioassay in order to detect IAA-like activity. Pea (P. sativum) was used as the test plant. The concentration of secreted IAA in the culture supernatant increased with the culture age. A gradual change in the root parameters (root length and number of lateral roots) was observed with the concentration of IAA. The concentration of auxin in or near roots is critical because a slight change results in a change in root length. On the one hand, IAA in low concentration causes an increase in root length; on the other hand, above a critical concentration, auxin inhibits the growth of the root or even causes a decrease of its length. This threshold concentration varies between different plants [12, 29]. Highly significant correlations were found between the concentration of IAA in the supernatant and the root parameters (root length and number of lateral roots). This could indicate an involvement of cyanobacterial IAA in the regulation of root growth [3]. Thus, the rhizospheric cyanobacteria showed useful traits (auxin synthesis and biofilm formation that possibly lead to intense root colonization) in vitro, as they do in nature. This ability of rhizospheric cyanobacteria can be exploited for agriculture.

\section{Acknowledgments}

The Higher Education Commission of Pakistan is acknowledged for funding the visit of Mehboob Ahmed to the Netherlands Institute of Ecology (NIOO-KNAW) (IRSIP No.1-8 HECHRD 2007 923). We thank Mrs. Anita Wijnholds for assistance with confocal laser scanning microscopy.

\section{References}

1. Ahmed M. 2011. Cyanobacterial secondary metabolites: their impact on plant growth and fertility status of soil. Ph.D.
Thesis. University of the Punjab, Lahore, Pakistan.

2. Ahmed M, Stal LJ, Hasnain S. 2010. Association of nonheterocystous cyanobacteria with crop plants. Plant Soil 336: 363-375.

3. Ahmed M, Stal LJ, Hasnain S. 2010. Production of indole-3acetic acid by the cyanobacterium Arthrospira platensis strain MMG-9. J. Microbiol. Biotechnol. 20: 1259-1265.

4. Ahmed M, Stal LJ, Hasnain S. 2011. DTAF: an efficient probe to study cyanobacterial-plant interaction using confocal laser scanning microscopy (CLSM). J. Ind. Microbiol. Biotechnol. 38: 249-255.

5. Amzallag GN, Vaisman J. 2006. Influence of brassinosteroids on initiation of the root gravitropic response in Pisum sativum seedlings. Biol. Plant 50: 283-286.

6. Badri DV, Weir TL, van der Lelie D, Vivanco JM. 2009. Rhizosphere chemical dialogues: plant-microbe interactions. Curr. Opin. Biotechnol. 20: 642-650.

7. Bais HP, Weir TL, Perry LG, Gilroy S, Vivanco JM. 2006. The role of root exudates in rhizosphere interactions with plants and other organisms. Annu. Rev. Plant Biol. 57: 233266.

8. Barazani O, Friedman J. 1999. Is IAA the major root growth factor secreted from plant-growth-mediating bacteria? J. Chem. Ecol. 25: 2397-2406.

9. Berendsen RL, Pieterse CM, Bakker PA. 2012. The rhizosphere microbiome and plant health. Trends Plant Sci. 17: 478-486.

10. Bergman B, Zheng WW, Klint J, Ran L. 2008. On the origin of plants and relations to contemporary cyanobacterial-plant symbioses. Plant Biotechnol. 25: 213-220.

11. Bladergroen MR, Spaink HP. 1998. Genes and signal molecules involved in the rhizobia-leguminoseae symbiosis. Curr. Opin. Plant Biol. 1: 353-359.

12. Callis J. 2005. Plant biology: auxin action. Nature 435: 436437.

13. Davies K, Whitbread R. 1989. Factors affecting the colonisation of a root system by fluorescent pseudomonads: the effects of water, temperature and soil microflora. Plant Soil 116: 247-256.

14. Dey R, Pal KK, Tilak KVBR. 2012. Influence of soil and plant types on diversity of rhizobacteria. Proc. Natl. Acad. Sci. India B Biol. Sci. 82: 341-352.

15. Dunlap JR, Robacker KM. 1988. Nutrient salts promote light-induced degradation of indole-3-acetic-acid in tissueculture media. Plant Physiol. 88: 379-382.

16. Fierer N, Jackson RB. 2006. The diversity and biogeography of soil bacterial communities. Proc. Natl. Acad. Sci. USA 103: 626-631.

17. Gaudes A, Sabater S, Vilalta E, Munoz I. 2006. The nematode community in cyanobacterial biofilms in the river Llobregat, Spain. Nematology 8: 909-919.

18. Glickmann E, Dessaux Y. 1995. A critical examination of the specificity of the Salkowski reagent for indolic compounds produced by phytopathogenic bacteria. Appl. Environ. Microbiol. 
61: 793-796.

19. Guevara E, Jiménez VM, Herrera J, Bangerth F. 2008. Effect of hydrogen cyanamide on the endogenous hormonal content of pea seedlings (Pisum sativum L.). Braz. J. Plant Physiol. 20: 159-163.

20. Gutierrez CK, Matsui GY, Lincoln DE, Lovell CR. 2009. Production of the phytohormone indole-3-acetic acid by estuarine species of the genus Vibrio. Appl. Environ. Microbiol. 75: 2253-2258.

21. Halliday KJ, Martinez-Garcia JF, Josse EM. 2009. Integration of light and auxin signaling. Cold Spring Harb. Perspect. Biol. 1: 1-11.

22. Höckelmann C, Jüttner F. 2004. Volatile organic compound (VOC) analysis and sources of limonene, cyclohexanone and straight chain aldehydes in axenic cultures of Calothrix and Plectonema. Water Sci. Technol. 49: 47.

23. Hussain A, Hasnain S. 2011. Phytostimulation and biofertilization in wheat by cyanobacteria. J. Ind. Microbiol. Biotechnol. 38: 85-92.

24. Hussain A, Hasnain S. 2012. Comparative assessment of the efficacy of bacterial and cyanobacterial phytohormones in plant tissue culture. World J. Microbiol. Biotechnol. 28: 14591466.

25. Khalid A, Arshad M, Zahir ZA. 2006. Phytohormones: microbial production and applications, pp. 207-220. In Uphoff N, Ball AS, Fernandes E, Herren H, Husson O, Laing M, et al. (eds.). Biological Approaches to Sustainable Soil Systems. Taylor \& Francis/CRC, Boca Raton, Florida

26. Klock J-H, Wieland A, Seifert R, Michaelis W. 2007. Extracellular polymeric substances (EPS) from cyanobacterial mats: characterisation and isolation method optimisation. Mar. Biol. 152: 1077-1085.

27. Kusaka N, Maisch J, Nick P, Hayashi K, Nozaki H. 2009. Manipulation of intracellular auxin in a single cell by light with esterase-resistant caged auxins. Chembiochem 10: 21952202.

28. Lambers H, Mougel C, Jaillard B, Hinsinger P. 2009. Plantmicrobe-soil interactions in the rhizosphere: an evolutionary perspective. Plant Soil 321: 83-115.

29. Lambers H, Pons TL, Chapin FS. 2008. Plant Physiological Ecology. Springer, New York.

30. Lau S, Jurgens G, De Smet I. 2008. The evolving complexity of the auxin pathway. Plant Cell 20: 1738-1746.

31. Mazhar S, Cohen JD, Hasnain S. 2013. Auxin producing non-heterocystous Cyanobacteria and their impact on the growth and endogenous auxin homeostasis of wheat. $J$. Basic Microbiol. 53: 996-1003.

32. McNear Jr DH. 2013. The rhizosphere - roots, soil and everything in between. Nature Educ. Knowledge 4: 1.

33. Morgan JAW, Bending GD, White PJ. 2005. Biological costs and benefits to plant-microbe interactions in the rhizosphere. J. Exp. Bot. 56: 1729-1739.

34. Okon Y, Vanderleyden J. 1997. Root-associated Azospirillum species can stimulate plants. ASM News 63: 366-370.

35. Ortiz-Castro R, Contreras-Cornejo HA, Macias-Rodriguez L, Lopez-Bucio J. 2009. The role of microbial signals in plant growth and development. Plant Signal Behav. 4: 701-712.

36. Pain R, Duggan PS, Adams DG. 2000. Creation of a tryptophan auxotroph to study the role of tryptophan in heterocyst development. Abstracts of the 10th International Symposium on Phototrophic Prokaryotes, Barcelona, Spain, August 26-31, 2000.

37. Pentecost A, Whitton BA. 2012. Subaerial Cyanobacteria, pp. 291-316. In Whitton BA (ed.). Ecology of Cyanobacteria II: Their Diversity in Space and Time. Springer, The Netherlands

38. Prasanna R, Jaiswal P, Nayak S, Sood A, Kaushik BD. 2009. Cyanobacterial diversity in the rhizosphere of rice and its ecological significance. Indian J. Microbiol. 49: 89-97.

39. Rippka R, Herdman M. 1992. Pasteur Culture Collection of Cyanobacteria: Catalogue and Taxonomic Handbook. I. Catalogue of Strains, Institut Pasteur, Paris.

40. Ryu RJ, Patten CL. 2008. Aromatic amino acid-dependent expression of indole-3-pyruvate decarboxylase is regulated by TyrR in Enterobacter cloacae UW5. J. Bacteriol. 190: 72007208.

41. Sabrine H, Afif H, Mohamed B, Hamadi B, Maria H. 2010. Effects of cadmium and copper on pollen germination and fruit set in pea (Pisum satioum L.). Sci. Horticult. 125: 551555.

42. Sergeeva E, Liaimer A, Bergman B. 2002. Evidence for production of the phytohormone indole-3-acetic acid by cyanobacteria. Planta 215: 229-238.

43. Smýkal P, Aubert G, Burstin J, Coyne CJ, Ellis NT, Flavell AJ, et al. 2012. Pea (Pisum sativum L.) in the genomic era. Agronomy 2: 74-115.

44. Spaepen S, Vanderleyden J, Remans R. 2007. Indole-3-acetic acid in microbial and microorganism-plant signaling. FEMS Microbiol. Rev. 31: 425-448.

45. Tabei Y, Okada K, Makita N, Tsuzuki M. 2009. Lightinduced gene expression of fructose 1,6-bisphosphate aldolase during heterotrophic growth in a cyanobacterium, Synechocystis sp. PCC 6803. FEBS J. 276: 187-198.

46. Tandeau de Marsac N, Houmard J. 1988. Complementary chromatic adaptation: physiological conditions and action spectra. Methods Enzymol 167: 318-328.

47. Tao Y, Ferrer JL, Ljung K, Pojer F, Hong F, Long JA, et al. 2008. Rapid synthesis of auxin via a new tryptophandependent pathway is required for shade avoidance in plants. Cell 133: 164-176.

48. Yuan ZC, Liu P, Saenkham P, Kerr K, Nester EW. 2008. Transcriptome profiling and functional analysis of Agrobacterium tumefaciens reveals a general conserved response to acidic conditions ( $\mathrm{pH}$ 5.5) and a complex acid-mediated signaling involved in Agrobacterium-plant interactions. J. Bacteriol. 190: 494-507. 